\title{
Correction: Estimating temporary populations: a systematic review of the empirical literature
}

\author{
Radoslaw Panczak (1D, Elin Charles-Edwards \& Jonathan Corcoran
}

Correction to: Humanities and Social Sciences Communications https://doi.org/10.1057/s41599-020-0455-y, published online 06 May 2020.

The original version of the paper included mistakes in the acknowledgements.

The incorrect acknowledgements section read:

This research is conducted through a project funded by the Australian Research Council Linkage Project grant LP160100305 with additional support from the industry partner the Australian Bureau of Statistics (ABS). Notably, the interpretations are solely those of the authors and do not necessarily reflect the views and opinions of the ABS or any of its employees.

The correct acknowledgements section now reads:

The authors wish to thank the Australian Bureau of Statistics (ABS), in particular, Denise Carlton, Andrew Howe, Anthony Grubb, Glen West, Beidar Cho and Karen Ecclestone of ABS for their input on various aspects of the paper. However, the interpretations of the analysis are solely those of the authors and do not necessarily reflect the views and opinions of the ABS or any of their employees. We would like to also thank the authors that responded to queries about details of their work: Christoph Aubrecht, Filipe Batista e Silva, Andrew Collins, Donald G. Janelle, Nik Lomax, David Martin, Chris Needham, Andy Newing, Paola Pucci, Stanley Smith and Martijn Tennekes. This research was funded by the Australian Government through the Australian Research Council Linkage project scheme, LP160100305.

This has been corrected in both the online and PDF article file.

Published online: 02 October 2020

\footnotetext{
(c) (i) Open Access This article is licensed under a Creative Commons Attribution 4.0 International License, which permits use, sharing, adaptation, distribution and reproduction in any medium or format, as long as you give appropriate credit to the original author(s) and the source, provide a link to the Creative Commons license, and indicate if changes were made. The images or other third party material in this article are included in the article's Creative Commons license, unless indicated otherwise in a credit line to the material. If material is not included in the article's Creative Commons license and your intended use is not permitted by statutory regulation or exceeds the permitted use, you will need to obtain permission directly from the copyright holder. To view a copy of this license, visit http://creativecommons.org/licenses/by/4.0/.
} 